\title{
Effects of lifestyle, personality, symptoms of anxiety and depression, and genetic predisposition on subjective sleep disturbance and sleep pattern
}

\author{
Andrew C Heath ${ }^{1}$, Lindon JEaves ${ }^{2}$, Katherine M Kirk ${ }^{3}$ and Nicholas G Martin ${ }^{3}$ \\ ${ }^{1}$ Department of Psychiatry, Washington University School of Medicine, St Louis, Missouri \\ ${ }^{2}$ Institute of Psychiatric and Behavioral Genetics, Medical College of Virginia, Richmond, Virginia, USA \\ ${ }^{3}$ Queensland Institute of Medical Research, Brisbane, Australia
}

\begin{abstract}
The effects on sleep pattern ('short-sl eep' versus 'long-sleep') and subjective sleep disturbance of genotype, personality, symptoms of anxiety and depression, and lifestyle, were examined using survey data on a clinically unselected sample of adult Australian twin pairs, aged 17-88 years. When the effects of genotype, per sonality and symptoms were ignor ed, lifestyle variables appeared to account for roughly $4 \%$ of the variance in sleep disturbance, and $9 \%$ of the variance in sleep pattern. Significant genetic effects on sleep disturbance and sleep pattern were found, which were only partly explained by the effects of personality and symptoms of anxiety and depression. Much of the association between sleep disturbance and lifestyle appeared to be explained by separate effects of personality and symptoms of anxiety and depression on sleep and lifestyle ('genotyperisk-factor correlation'). There was little evidence for genetically determined differences in sensitivity to the lifestyle variables ('genotype $\times$ risk-factor interaction').
\end{abstract}

Keywords: sleep, genetics, twins, personality

\section{Introduction}

Sleep disturbance is the second most common symptom of mental distress. ${ }^{1}$ According to some surveys, as much as one third of the adult population reports difficulty sleeping. ${ }^{1-6}$ This high frequency of complaints about sleep is reflected in the widespread use of prescribed hypnotic medication and non-prescription remedies., ${ }^{2,6}$ Sleep disturbance is often a chronic complaint, one study finding that over $40 \%$ of those reporting sleep problems have had them for more than 5 years. ${ }^{4}$ Compared with the general population, individuals reporting disturbed sl eep are more likely to report persistent or recurrent heal th problems, or emotional distress. ${ }^{4}$ It is usually difficult to determine whether sleep disturbance is a cause or a consequence of such problems. In one major prospective investigation of the effects of insomnia on occupational performance, a longitudinal study of sailors in the navy, however, poor sl eepers were subsequently found to be less effective in their work, less likely to receive promotion and more likely to be demoted, discharged, or not re-enlisted.

Correspondence Dr NG Martin, Queensland Institute of Medical Research, Post Office, Royal Brisbane Hospital, Brisbane QLD 4029 Australia. Tel: +61733620278; Fax: + 61733620101 ; E-mail: nickM@imr.edu.au

Received 1 September 1998; accepted 8 September 1998
Deviant sleep pattern has also been identified as a potentially important problem for physical health. Those who report Ionger than average sleep duration ('long-sleepers'), as well as those reporting short sleep duration ('short-sl eepers'), have been shown to have an increased risk of mortality, ${ }^{8-12}$ which cannot be explained by previous history of coronary heart disease, stroke, diabetes, or high blood pressure. ${ }^{10}$

Risk factors for subjective sl eep disturbance in the general population have been examined in several major epidemiological surveys. The prevalence of various forms of sleep disturbance has been found to be greater in females, ${ }^{1-3,5,6,8,13-15}$ in older age cohorts, ${ }^{3-6,8,13-16}$ and in those with lower educational level, lower income or lower socioeconomic status. ${ }^{3,4,15,16}$ Some studies have attempted to identify more detailed aspects of lifestyle (eg smoking and drinking) which are predictive of subjective sleep disturbance and sleep pattern. ${ }^{17-21}$

Other research has focused upon the importance of biological factors in sleep disturbance and sleep pattern. Studies of inbred mouse strains have suggested a genetic basis to differences in sleep pattern, ${ }^{22,23}$ and a significant proportion of variance in some components of human sleep has also been demonstrated to be genetically determined. ${ }^{24,25}$ Twin studies have shown substantial genetic effects in somnambulism ${ }^{26}$ and narcolepsy, ${ }^{27}$ with a predisposing genetic factor for the latter recently identified. ${ }^{28,29}$ Investigation of the first-degree relatives of probands with clinical disturbances of sleep have 
shown significant familial aggregation for hypersomnia ${ }^{30,31}$ and sleep apnea. ${ }^{32} \mathrm{~A}$ study of Finnish twins, ${ }^{33}$ which included brief items about duration and quality of sleep in a more general health survey, has suggested a significant genetic effect on both these variables in a clinically unsel ected population. Using data from an extensive survey of adult twins from the Australian twin panel ${ }^{34}$ we have found a significant genetic effect on liability to symptoms of anxiety and depression, including sleep disturbance associated with worrying or feeling miserable. ${ }^{35}$ Statistical analysis of the genetic and environmental causes of the covariation of symptoms of anxiety and depression has revealed a dimension of genetic liability to sleep disturbance which is independent of liability to anxiety and depression. ${ }^{36}$ Further analyses using data from a more detailed investigation of sleep patterns and sleep difficulties, carried out as part of the same survey, have confirmed the importance of genetic liability to sl eep disturbance and revealed an even more important effect of genotype on sl eep pattern. ${ }^{37}$

\section{Genotype $\times$ risk factor interaction}

A weakness of these studies has been their exclusive focus upon the predisposing role of either genetic factors, or epidemiological risk factors. This ignores the possible importance of genotype $\times$ environment interaction. ${ }^{38-41}$ If sensitivity to risk factors is partly under genetic control or if the importance of genetic predisposition varies under different environmental conditions ('genotype $\times$ risk factor interaction'), attempts to estimate the average effects of genetic differences (ignoring differences in risk factor exposure) or of risk factors (ignoring differences in genetic predisposition) would be misleading. Risk factors for sl eep disturbance might be important only in a few individuals at high genetic risk. Genetic predisposition might be important only in those individuals exposed to risk factors for sleep disturbance. If genotype $\times$ environment interaction is a major factor in sleep disturbance, this would have important implications for sleep laboratory research. If poor sleepers are genetically 'sensitised' to lifestyle risk factors and to disturbances in their home environment, we would not expect to obtain accurate estimates of normal sleep disturbance in the restricted environment of the sleep laboratory.

\section{Pathways from genotype to sleep disturbance}

The joint analysis of genetic factors and risk-factors al so allows us to detect genotype-risk factor correlation. ${ }^{38}$ It is commonly assumed that a genetic contribution to liability implies a fairly direct pathway from genotype to the disorder. However, we know that there are genetic influences on personality, ${ }^{43}$ on liability to symptoms of anxiety and depression, ${ }^{34-36}$ and on a variety of lifestyle variables such as smoking, ${ }^{44-46}$ al cohol consumption ${ }^{42,46}$ and caffeine consumption. ${ }^{46}$ Thus the mere demonstration that there are genetic influences on sleep disturbance and sleep pattern tells us nothing about the pathway from genotype to outcome. Effects of symptoms, personality and lifestyle on sleep could explain the genetic variation.

Genotype-risk factor correlation poses a problem equally for epidemiological studies as well as genetic analyses. It is usually assumed that a risk factor is having a direct causal effect on a disorder. However, it is also possible that an apparent risk factor is determined by an intervening variable which is influencing the disorder, and that the risk factor itself is having no direct causal effect. Thus an association between lack of physical exercise and sleep disturbance might arise because symptoms of anxiety and depression, or some predisposing personal ity variables, give rise to sl eep disturbance and, separately, to reduced physical activity. No causal effect of physical exercise on sleep need be implied.

The analysis of genotype $\times$ risk factor interaction, and genotype-risk factor covariation, is possibly only when sleep disturbance, sleep pattern and their associated risk factors are studied in a genetically informative design (eg twins or adoption data). In the Australian twin survey, self-report measures of psychological distress, subjective sleep duration and sleep pattern, personality, and a variety of aspects of lifestyle were obtained. In this paper we present the results of joint analyses of the effects of genetic and epidemiological factors, and their covariation and interaction, on sleep disturbance and sleep pattern.

\section{Methods}

\section{Subjects}

A questionnaire, including items about sleep patterns and sleep difficulties, ${ }^{20,47-49}$ symptoms of anxiety and depression, ${ }^{50,51}$ personality, ${ }^{52}$ drug usage and other habits potentially rel ated to sleep (eg alcohol consumption, smoking ${ }^{42,45}$ ), was mailed to all adult twins enrolled in the Australian NH \& MRC Twin Register. ${ }^{34}$ Questionnaires were mailed to 5967 twin pairs aged 17 years or greater in 1980-1982. Ages of respondents ranged from 17 to 88 years. After one or two reminders to non-respondents, completed questionnaires were returned by both members of 2903 same-sex twin pairs (1233 female and 567 male monozygotic (MZ) twin pairs, 751 female and 352 male dizygotic (DZ) twin pairs). To simplify the genetic and genetic-epidemiological 
analyses, 907 opposite-sex pairs were excluded. A two-item zygosity questionnaire was used to determine zygosity. ${ }^{34}$ Such questionnaires have been shown to give $95 \%$ agreement with diagnosis based on extensive blood-typing. ${ }^{53-57}$ A total of 15 respondents admitted to regular use of 'sleeping tablets' or 'tranquillisers'. Since this number is far too small to have a major biasing effect on our analyses, these individuals were not excluded from the sample.

\section{Measures}

Items from the sleep questionnaire of $\mathrm{Jhns}^{20,47-49}$ were selected for the present study. Responses to these questions have been shown to give good agreement with laboratory-based EEG measures of sleep, ${ }^{58}$ and to show good consistency over time. ${ }^{47,48}$ Measures of subjective sleep quality and sleep disturbance were as follows (see Tables 1 and 2 for response al ternatives):

(i) Overall quality: 'How would you describe the quality of your usual sleep over the last few months?;

(ii) Variability of quality: 'How much would you say the quality of your sleep varies from one night to the other?;

(iii) Depth of sleep: 'How would you describe the depth of your sleep?;

(iv) Initial insomnia: 'How often does it take you much longer than usual to get off to sleep?;

Table 1 Distribution of responses (percentage) to quasicontinuous sleep variables, by sex

\begin{tabular}{lll}
\hline & Males $(\mathrm{n}=1838)$ & Females $(\mathrm{n}=3968)$ \\
\hline Bedtime & & \\
21.45 or before & 15.3 & 22.3 \\
$21.46-22.29$ & 20.9 & 24.8 \\
$22.30-22.59$ & 23.1 & 25.3 \\
23.00 & 20.0 & 16.6 \\
after 23.00 & 20.7 & 11.0 \\
Sleeptime & & \\
22.00 or before & 22.7 & 28.6 \\
22.01-22.30 & 20.2 & 23.5 \\
22.31-23.00 & 24.5 & 23.7 \\
23.01-23.30 & 15.4 & 13.3 \\
after 23.30 & 17.2 & 10.9 \\
Sleep latency & & \\
0-9 minutes & 25.9 & 24.3 \\
10-14 minutes & 21.6 & 20.2 \\
15-29 minutes & 24.9 & 23.0 \\
30-59 minutes & 20.4 & 21.0 \\
60+ minutes & 7.3 & 11.5 \\
Sleep duration & & \\
less than 7 hours & 15.2 & 12.3 \\
7-7.49 hours & 22.0 & 18.0 \\
7.5-7.99 hours & 15.0 & 10.8 \\
8-8.5 hours & 37.4 & 44.3 \\
greater than 8.5 hours & 10.6 & 15.4 \\
\hline
\end{tabular}

(v) Night waking 'How often do you wake up fully during the night?;

(vi) Daytime napping: 'How often do you doze or sleep during the day (including evenings before going to bed and weekends)?'

Two items from the Delusions-Symptoms-States Inventory ${ }^{50,51}$ also concern problems of sleep: 'Recently, worrying has kept me awake at night' (anxious insomnia) and 'Recently I have been so miserable that I have had difficulty with my sleep' (depressed insomnia). The questionnaire also included items about the usual times (on weekdays) when the respondent

(i) goes to bed (which we shall refer to as 'bedtime');

(ii) tries to get to sleep ('sleep-time');

(iii) how long the respondent takes to get to sleep, ('sleep latency'); and

(iv) how long the respondent sleeps ('sleep duration').

In addition to these sleep items, the questionnaire contained items on marital status and family structure, educational level, smoking (average daily consumption), alcohol consumption (typical weekly consumption), consumption of tea and coffee (number of cups per day) and amount of physical exercise (1 - jogging, cycling to work or vigorous sport 3-4 times a week; 2 - play sport or exercise a couple of times a week; 3 - regular exercise (eg tennis, golf, etc) about once a week; 4 - occasional exercise (2-3 times a month) or regular light gardening; 5 - none). The use of decaffeinated products in Australia at the time of the study was considered to be sufficiently infrequent not to necessitate any distinction between regular and decaffeinated tea and coffee. Measures of extraversion, neuroticism, and recent symptoms of anxiety and depression, were al so included in some analyses, after excluding items which made specific reference to sleep.

\section{Data summary}

All the sleep variables, with the exception of bedtime, sleeptime, sleep latency and sleep duration, were assessed using a discontinuous scale. For the 'quality of sleep' variable, we collapsed categories 4 and 5 ('poor' and 'very poor'), since the frequency of responses falling into category 5 was extremely low. When we examined the frequency distribution of responses to bedtime, sleeptime, sleep latency and sleep duration items, these too were found to be discontinuous, responses being clustered around hours, or 15,30 or 45 minutes past 
Table 2 Distribution (\%) of discontinuous sleep variables, by sex (1838 males, 3968 females)

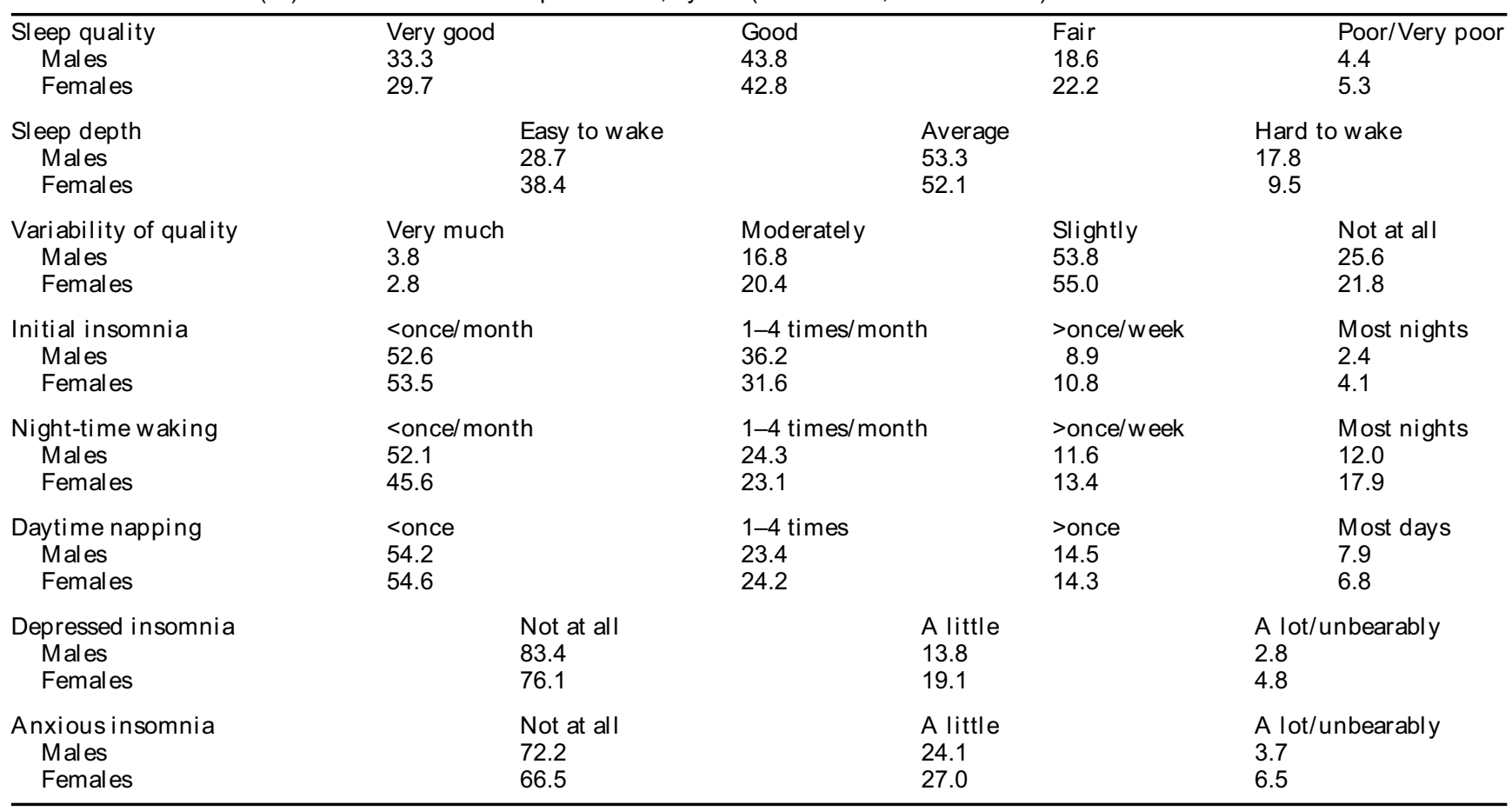

an hour. We therefore recorded these variables as discontinuous five point scales (see Table1).

To avoid performing multiple significance tests on correlated measures of sleep pattern and sleep disturbance, a principal components analysis was performed, separately for each sex, and component scores on three orthogonal dimensions were derived. Scores by each member of a twin pair were included in the same analysis, ignoring the non-independence of observations on twin pairs.

\section{Data analysis}

To explore the joint effects of epidemiological 'risk factors' and genetic factors, and their interaction, we have used an approach based upon regression analysis. ${ }^{59}$ More powerful methods based upon structural equation modelling ${ }^{60}$ were considered, but these would have required extensive computing, and were therefore deemed inappropriate for exploring the effects of a large number of risk factors, and their interaction with genotype.

In a conventional regression analysis, sleep scores, $S$, would be predicted as a linear function of the epidemiological variables $E_{1}, E_{2}, E_{3}$ etc

$$
S=b_{0}+b_{1} E_{1}+b_{2} E_{2}+b_{3} E_{3}+\ldots+e .
$$

To allow for genetic effects on $\mathrm{S}$, we included in the regression analysis a term for the interaction of zygosity (coded 1 for identical twin pairs, 0.5 for fraternal twin pairs) and the co-twin's score on $S, S_{C}$.
This will test whether there is a significant regression of twin's score on co-twin's score which varies as a function of the degree of genetic relatedness (as would be predicted if there are genetic influences on sleep which are not purely mediated through the measured epidemiological risk factors). To test hypotheses about the intervening variables (extraversion, neuroticism, and symptoms of anxiety and depression) which might account for genetic effects on $S$ (including genotype-risk factor covariation), we included in the regression equation terms for the interaction of zygosity with co-twin's score on the other variables, before adding in the $z y g \times S_{C}$ interaction term. This in effect partitions the genetic variance in $S$ into that which is mediated through these other variables and any residual genetic variance which is specific to sleep. To test for genotype $\times$ risk factor interaction, we then included further terms involving the three-way interaction of zygosity, co-twin's score (on either sleep or some other 'mediating' variable, M), and twin's risk factor. Thus our full regression equation had the form

$$
\begin{aligned}
\mathrm{S}=\mathrm{b}_{0} & +\sum \mathrm{b}_{\mathrm{i}} \mathrm{E}_{\mathrm{i}}+\mathrm{b}_{\mathrm{c}}\left(z \mathrm{zyg} \times \mathrm{S}_{\mathrm{c}}\right)+\sum \mathrm{b}_{\mathrm{j}}\left(z \mathrm{yg} \times \mathrm{S}_{\mathrm{c}} \times \mathrm{E}_{\mathrm{j}}\right) \\
& +\sum \mathrm{b}_{\mathrm{k}}\left(z \mathrm{zyg} \times \mathrm{M}_{\mathrm{k}}\right)+\sum \sum \mathrm{b}_{\mathrm{k}, \mathrm{m}}\left(\mathrm{zyg} \mathrm{g} \times \mathrm{M}_{\mathrm{k}} \times \mathrm{E}_{\mathrm{m}}\right) .
\end{aligned}
$$

Since it is largely the same genes which are responsible for neuroticism and symptoms of anxiety and depression, ${ }^{34-36}$ we tested for three-way interactions involving zygosity and co-twin's neuroticism score, but not co-twin's anxiety or depression scores. 
Table 3 Loadings of sleep variables on three orthogonal principal components

\begin{tabular}{|c|c|c|c|c|c|c|}
\hline & \multicolumn{3}{|c|}{ Females } & \multicolumn{3}{|c|}{ Males } \\
\hline & I & II & III & I & II & III \\
\hline $\begin{array}{l}\text { Quality } \\
\text { Variability } \\
\text { Depth }\end{array}$ & $\begin{array}{r}0.77 \\
0.64 \\
-0.35\end{array}$ & $\begin{array}{r}-0.14 \\
-0.09 \\
0.13\end{array}$ & $\begin{array}{l}0.00 \\
0.04 \\
0.33\end{array}$ & $\begin{array}{r}0.79 \\
0.56 \\
-0.40\end{array}$ & $\begin{array}{r}-0.11 \\
-0.13 \\
0.14\end{array}$ & $\begin{array}{r}-0.10 \\
-0.00 \\
0.52\end{array}$ \\
\hline $\begin{array}{l}\text { Initial insomnia } \\
\text { Sleep latency } \\
\text { Night-time waking } \\
\text { Anxious insomnia } \\
\text { Depressed insomnia }\end{array}$ & $\begin{array}{l}0.70 \\
0.54 \\
0.47 \\
0.67 \\
0.64\end{array}$ & $\begin{array}{l}-0.07 \\
-0.08 \\
-0.25 \\
-0.07 \\
-0.09\end{array}$ & $\begin{array}{r}0.05 \\
0.29 \\
-0.47 \\
-0.21 \\
0.19\end{array}$ & $\begin{array}{l}0.74 \\
0.60 \\
0.51 \\
0.70 \\
0.66\end{array}$ & $\begin{array}{l}-0.07 \\
-0.06 \\
-0.18 \\
-0.07 \\
-0.10\end{array}$ & $\begin{array}{r}0.03 \\
0.10 \\
-0.48 \\
0.43 \\
0.44\end{array}$ \\
\hline $\begin{array}{l}\text { Bedtime } \\
\text { Sl eeptime } \\
\text { Sleep duration } \\
\text { Frequency of napping }\end{array}$ & $\begin{array}{r}0.16 \\
0.20 \\
-0.30 \\
0.13\end{array}$ & $\begin{array}{r}0.92 \\
0.92 \\
-0.57 \\
0.07\end{array}$ & $\begin{array}{r}0.03 \\
0.05 \\
0.23 \\
-0.74\end{array}$ & $\begin{array}{r}0.12 \\
0.22 \\
-0.41 \\
0.09\end{array}$ & $\begin{array}{r}0.93 \\
0.91 \\
-0.50 \\
-0.03\end{array}$ & $\begin{array}{r}0.01 \\
0.02 \\
0.27 \\
-0.37\end{array}$ \\
\hline
\end{tabular}

Loadings greater than 0.3 are show $n$ in bold

In view of the evidence for important effects of age on sleep (see references above), in all analyses age was al ways included as the first term in the regression equation. Initially, we attempted to predict sleep disturbance and sleep pattern using only age and the other epidemiological variables. We then attempted to improve prediction by adding in successively terms representing genetic effects, effects of the interaction of genotype with the epidemiological variables, and finally effects of symptoms of distress and personality. At each stage, all terms which had been found to be significant at any preceding stage were forced into the regression equation.

As an alternative approach, we then examined the improvement in prediction which occurs when sleep disturbance and sleep pattern is predicted initially from age, genetic effects and personality and symptoms, and only afterwards were the other epidemiological variables, and terms for their interaction with genotype, included in the regression equation. If the epidemiological variables are having a direct, causal effect on sleep, we would expect the main effects of these variables to remain significant. If, however, they are merely indices of personality, symptoms or other factors which influence sleep, and are themsel ves having no direct causal effect, we would expect their effects to be non-significant.

\section{Results \\ Effects of sex}

Contingency tables were computed, cross-classifying the sleep pattern and sleep disturbance variables by sex (see Tables 1 and 2). Consistent with findings in other populations, Australian women report that they sleep more poorly $\left(\chi_{3}^{2}=15.54, \mathrm{P}<0.001\right)$ and more lightly $\left(\chi_{2}^{2}=107.88, P<0.001\right)$ than do their mal e counterparts, and that the quality of their sleep varies more from night to night $\left(\chi_{3}^{2}=21.84\right.$,
$P<0.001)$. They more frequently have difficulty in falling asleep $\left(\chi_{3}^{2}=23.27, P<0.001\right)$, have a longer sleep latency $\left(\chi_{4}^{2}=26.45, P<0.001\right)$, and are more likely to wake up fully during the night $\left(\chi_{3}^{2}=41.34\right.$, $P<0.001)$. Australian women are also more likely than men to report sleep disturbance because of worrying $\left(\chi_{2}^{2}=27.90, P<0.001\right)$ or feeling miserable $\left(\chi_{2}^{2}=41.05, P<0.001\right)$. They go to bed earlier $\left(\chi_{4}^{2}=131.12, P<0.001\right)$, try to get to sleep earlier $\left(\chi_{4}^{2}=60.91, P<0.001\right)$ and actually sleep for longer than Australian men $\left(\chi_{4}^{2}=74.82, P<0.001\right)$. Unexpectedly, no significant sex difference in frequency of napping during the day was found $\left(\chi_{3}^{2}=2.29\right.$, $P=0.51)$.

\section{Multivariate analysis}

For each sex, the first three principal components accounted for over $50 \%$ of the variance in the sleep variables $(53.5 \%$ in males, $54.7 \%$ in females) and had eigenvalues greater than unity. Loadings on these principal components of the sleep variables (which may be interpreted as the correlations of each sleep variable with the corresponding component) are given in Table 3 . The first component is clearly a measure of general sl eep disturbance, with 'quality', 'variability of quality', 'initial insomnia', 'depressed insomnia', 'anxious insomnia', 'latency', and 'night waking' all having high loadings on this component, and 'depth' and 'duration' having moderate loadings. Despite the unusual wording of the 'initial insomnia' item, its high loading on the first component indicates that it is providing a useful measure of sleep disturbance. Only 'bedtime', 'sleeptime' and 'duration' have high loadings on the second component, which is clearly a measure of sleep pattern, distinguishing long-sleepers who go to bed early from short-sl eepers who go to bed late. In both sexes, sleep duration loads more heavily on the second component than on the first, implying that sleep 
pattern is a more important determinant of sleep duration than is sleep disturbance.

The first two components have very similar loadings in the two sexes, and are also very similar to factors obtained using a more extensive sleep questionnaire in other populations. ${ }^{20,49}$ The third component in males contrasts those who regularly nap during the day, and are shal low sl eepers whose sl eep is easily disturbed, with deep sleepers who do not take naps very frequently. Interpretation of the third component in females is more equivocal, but it appears to contrast shallow sl eepers whose sleep is easily disturbed, and who nap frequently, with those who suffer from 'anxious insomnia' and 'depressed insomnia'.

\section{Epidemiological predictors}

In females, sleep disturbance (assessed by scores on the first principal component) increases with age $\left(F_{1,3365}=28.87, \quad P<0.001\right)$, consumption of tea $(F=19.01, \quad P<0.001)$ and coffee $(F=17.31$, $P<0.001)$. Smoking is also associated with increased sleep disturbance, although not significantly so $(F=3.10, P=0.08)$. How ever, sleep disturbance is reduced by regular exercise $(F=12.39$, $P<0.001)$, and is al so decreased in married subjects $(F=38.07, P<0.001)$, and those more highly educated $(F=9.27, P<0.001)$. In males, sleep disturbance is decreased in married subjects $\left(F_{1,1593}=15.82, P<0.001\right)$, and is associated with increased use of hypnotic medication $(F=17.05$, $P<0.001)$, drinking $(F=12.34, P<0.001)$, having children $(F=5.17, P=0.02)$, and higher education (the opposite effect to that observed in females: $F=5.85, P<0.001)$. The harmful effects of coffee consumption $(F=3.61, P=0.06)$ and protective effects of regular exercise $(F=3.36, P=0.07)$ are just short of significant. These lifestyle and situational variables together accounted for only $3.9 \%$ of the variance in female sleep disturbance, and $3.4 \%$ of the variance in males.

Female short-sleepers are older $\left(F_{1,3362}=15.95\right.$, $P<0.001)$, better educated $(F=46.76, P<0.001)$, less likely to have children ( $F=20.50, P<0.001)$ and less likely to be married (although this association is not significant: $F=2.73, P=0.10$ ). They al so tend to drink less alcohol $(F=3.84, P=0.05)$. However, they are more likely to smoke $(F=32.40$, $P<0.001)$, drink tea and coffee $(F=32.66$, $P<0.001 ; F=3.84, P=0.05)$ and exercise regularly $(F=8.89, P=0.002)$.

Male short-sleepers are also better educated $\left(F_{1,1594}=69.98, P=0.001\right)$, less likely to be married $(F=11.69, P<0.001)$, and less likely to have children $(F=2.74, \quad P=0.10)$. They smoke more $(F=7.04, P<0.01)$, and drink more tea and coffee.
$(F=3.44, P=0.06 ; F=29.50, P<0.001)$. Together these variables account for $5.6 \%$ of the variance in scores on the second principal component by females, $8.5 \%$ of the variance in males.

For component scores on the third factor in females, we find that the best single predictor is age $\left(F_{1,3369}=193.13, P<0.001\right)$. In addition to being older, female shallow sleepers who wake at night and nap during the day are more likely to be married $(F=106.26, P<0.001)$ and less likely to smoke $(F=37.00, P<0.001)$. These variables account for $12.2 \%$ of the variance. In males, age is al so the best predictor of scores on the third factor $\left(F_{1,1594}=221.74, P<0.001\right)$. Male shallow sleepers who nap during the day are also more likely to be married $(F=8.44, P=0.004)$, and consume more alcohol $(F=9.30, P=0.002)$, less tea $(F=3.61$, $P=0.06)$, and less hypnotic medication $(F=4.23$, $P=0.04)$. They are less likely to smoke $(F=7.36$, $P=0.007)$, and also tend to be less well educated $(F=8.74, P=0.003)$. Together these variables predict $20.5 \%$ of the variance in scores on factor 3 in males.

\section{Incorporating genetic effects}

Including a term for the interaction of zygosity and co-twin's sleep score leads in every case to a significant improvement in prediction of the first twin's score. In femal es the proportion of variance in the twin's score accounted for increases to $12.1 \%$ in the case of the sleep disturbance component $\left(F_{1,3019}=83.73, P<0.001\right)$, to $13.4 \%$ for the shortsleep component $\left(\mathrm{F}_{1,3017}=271.60, \mathrm{P}<0.001\right)$ and to $16.1 \%$ for the third component $\left(F_{1,3023}=128.42\right.$, $\mathrm{P}<0.001)$. In males, the corresponding increases are to $8.3 \%$ for sleep disturbance $\left(\mathrm{F}_{1,1442}=70.75\right.$, $P<0.001$ ), to $16.2 \%$ for short-sleep component $\left(F_{1,1443}=84.91, P<0.001\right)$ and to $25.3 \%$ for the third sleep component $\left(F_{1,1443}=84.91, P<0.001\right)$. It should be noted that the degrees of freedom have decreased in these analyses incorporating genetic effects because of cases where data on the co-twin's sleep scores were missing. These results imply that there are significant genetic effects on sleep disturbance and sleep pattern which are not explained by the effects of smoking, drinking, and other risk factors.

\section{Partitioning the genetic variation}

In females, we found evidence for genetic effects on sleep disturbance mediated through neuroticism $\left(F_{1,3019}=23.60, P<0.001\right)$, introversion $(F=3.23$, $P<0.001)$, anxiety $(F=7.45, P=0.006)$ and depression $(F=4.40, P=0.04)$. The interaction of zygosity with co-twin's sleep disturbance $\left(F_{1,3015}=239.01\right.$, 
$P<0.001)$ was still found to be significant, ie there still remained significant residual genetic variance that was not mediated through these variates. In males, genetic effects on sleep disturbance mediated through anxiety $\left(\mathrm{F}_{1,1140}=11.91, \mathrm{P}<0.001\right)$ and introversion $(F=6.17, P=0.01)$ were found, but once again there was significant residual genetic variance in sleep disturbance $\left(F_{1,1436}=42.60\right.$, $\mathrm{P}<0.001)$.

Significant genetic effects on short-sleep versus long-sleep mediated through neuroticism were found in females $\left(F_{1,3015}=7.84, P=0.005\right)$ and in males $\left(F_{1,1440}=8.23, P=0.004\right)$, but again there was highly significant evidence for residual genetic variation in both sexes $\left(\mathrm{F}_{1,3014}=286.52, \mathrm{P}<0.001\right.$; $\left.F_{1,1439}=136.95, P<0.001\right)$. Similarly, some of the genetic variation in scores on the third component by female twins could be explained by genetic effects on neuroticism $\left(F_{1,3017}=7.10, P=0.008\right)$ and introversion $(F=4.17, P=0.04)$, but a highly significant genetic effect remained unexplained ( $F=165.96, P<0.001)$. For male twins, some of the genetic effects on shallow sleeping and napping could be explained by the effects of symptoms of anxiety and depression $\left(F_{1,1440}=3.02, \quad P=0.08\right.$; $F=8.09, P<0.01$ ), but once again the unexplained genetic effect was highly significant $\left(F_{1,1439}=81.14\right.$, $P<0.001)$. Thus, although some of the genetic variation in sleep disturbance and sleep pattern can be explained by the effects of genes which are influencing neuroticism (and anxiety and depression ${ }^{34,36}$ ) and, in the case of sleep disturbance, extraversion, much of the genetic variation cannot be explained by these intervening variables.

\section{Genotype $\times$ risk factor interaction}

In females, the addition of terms for the three-way interactions of zygosity, co-twin's score and own risk factors explained less than $0.4 \%$ of the variance in sleep disturbance, $0.9 \%$ of the variance in shortsleep, and $0.1 \%$ of the variance in scores on the third component. In males, corresponding proportions of variance explained were $0.9 \%, 1.1 \%$ and $0 \%$. Genotype $\times$ risk factor interaction does not appear to play a major role in sleep disturbance or sleep pattern.

For sleep disturbance in females, there was weak evidence for 'significant' interaction of zygosity, age and co-twin's sleep disturbance ('genotype $\times$ age interaction': $F_{1,3013}=8.64, P=0.003$ ). Apparently, the effects of genetic liability on sleep disturbance is increased in older women. There was also a significant interaction of zygosity, tea consumption and co-twin's neuroticism score ( $F=8.64, P=0.003)$; high tea consumption exacerbates the detrimental effects of high genetic liability to neuroticism.
In males, the effects of genetic liability to sleep disturbances are ameliorated by having children $\left(F_{1,1438}=6.01, P=0.01\right)$, despite the fact that the environmental main effect of having children is to increase the likelihood of complaints about sleep disturbance. The effects of high genetic liability to neuroticism are exacerbated by high alcohol consumption ( $F=7.85, P=0.005)$.

The impact of genetic liability on long-sleep in females is exacerbated by high al cohol consumption $\left(F_{1,3011}=6.56, P=0.01\right)$ and by smoking $(F=26.44$, $P=0.004)$. The association between genetic liability to neuroticism and long-sleep is also increased by coffee consumption ( $F=5.23, P=0.02)$, but diminished by having children $(F=4.01, P<0.05)$. The genetic correlation between extraversion and shortsleep is exacerbated by having children ( $F=6.00$, $P=0.01)$. In males, marriage tends to reduce the impact of genetic liability to short-sleep $\left(F_{1,1440}=12.88, \quad P<0.001\right)$, whilst education reduces the association between genetic liability to neuroticism and short-sleep $(F=5.95, P=0.01)$.

For frequent napping associated with shallow sleep, a significant three-way interaction of zygosity, co-twin's extraversion and own smoking was obtained in females $\left(F_{1,3020}=4.75, P=0.03\right)$. The association between genetic liability to extraversion and napping during the day is diminished by smoking. In males, there was no evidence for genotype $\times$ risk factor interaction, although the term for genotype $\times$ age interaction was just short of significance $\left(F_{1,1440}=2.75, P=0.10\right)$. Predictably, there is a tendency for genetic liability to frequent napping to become more important in older males.

Table 4 summarizes the major predictors of sleep disturbance and sleep pattern identified in these regression analyses.

\section{Effects of personality and symptoms}

When the regression equations were further elaborated by including own personality (extraversion and neuroticism) and recent symptoms of anxiety and depression, a major improvement in prediction was achieved for scores on the first sleep disturbance component. With these variables, however, we cannot be certain whether associations with sleep represent cause or effect. For females, significant effects of neuroticism $\left(F_{1,3010}=100.20, P<0.001\right)$, and symptoms of anxiety $(F=25.18, P<0.001)$ and depression ( $F=8.35, P<0.001)$ were found, and the proportion of variance accounted for in sleep disturbance score increased from $13 \%$ to $36.6 \%$. In males, too, the inclusion of neuroticism $\left(F_{1,1433}=49.24, \quad P<0.001\right), \quad$ anxiety $(F=73.84$, $P<0.001)$ and depression $(F=20.59, P<0.001)$ led to a significant improvement in prediction, from 
Table 4 Predictors of sleep disturbance and sleep pattern (excluding own personality and symptoms of anxiety and depression)

\begin{tabular}{|c|c|c|c|c|c|c|}
\hline & $\begin{array}{l}\text { Sleep disturbance } \\
\text { Female }\end{array}$ & Male & $\begin{array}{l}\text { Short sleep } \\
\text { Female }\end{array}$ & Male & $\begin{array}{l}\text { Frequen } \\
\text { shallow } \\
\text { Female }\end{array}$ & Male \\
\hline \multicolumn{7}{|l|}{ Epidemiological: } \\
\hline Age & $\uparrow\left({ }^{* * *}\right)$ & - & $\uparrow * *$ & - & $\uparrow * * *$ & $\uparrow * * *$ \\
\hline Education & $\downarrow\left({ }^{* * *}\right)$ & $\uparrow\left({ }^{* * *}\right)$ & $\uparrow * * *$ & $\uparrow * * *$ & - & $\downarrow^{* *}$ \\
\hline Marriage & $\downarrow^{* * *}$ & $\downarrow^{* * *}$ & $\downarrow^{*}$ & $\uparrow\left({ }^{* * *}\right)$ & $\uparrow * * *$ & $\uparrow * *$ \\
\hline Children & - & $\uparrow * *$ & $\downarrow$ ${ }^{* * *}$ & - & - & - \\
\hline Alcohol & - & $\uparrow\left({ }^{* * *}\right)$ & $\downarrow\left({ }^{*}\right)$ & - & - & $\uparrow * *$ \\
\hline Tea & $\uparrow\left({ }^{* * *}\right)$ & - & $\uparrow^{*}$ & - & - & - \\
\hline Coffee & $\uparrow * * *$ & - & $\uparrow * * *$ & $\uparrow * * *$ & - & - \\
\hline Exercise & $\downarrow^{* *}$ & - & $\uparrow *$ & - & - & - \\
\hline Smoking & - & - & $\uparrow * * *$ & $\uparrow\left({ }^{* * *}\right)$ & $\downarrow^{* * *}$ & $\downarrow^{* * *}$ \\
\hline \multicolumn{7}{|l|}{ Genetic: } \\
\hline Neuroticism (N) & $\uparrow(* * *)$ & - & $\uparrow\left({ }^{* *}\right)$ & $\uparrow\left(^{* *}\right)$ & $\uparrow * *$ & - \\
\hline Extraversion (E) & $\downarrow^{* * *}$ & $\downarrow^{* *}$ & - & - & $\downarrow\left({ }^{* *}\right)$ & - \\
\hline Anxiety $(A n x)$ & $\uparrow\left({ }^{* * *}\right)$ & $\uparrow\left({ }^{* * *}\right)$ & - & - & - & - \\
\hline Depression (Dep) & $\uparrow(* * *)$ & - & - & - & - & $\downarrow\left(^{* *}\right)$ \\
\hline Residual (G) & $\uparrow * * *$ & $\uparrow * * *$ & $\uparrow * * *$ & $\uparrow * * *$ & $\uparrow * * *$ & $\uparrow^{* * *}$ \\
\hline \multicolumn{7}{|c|}{ Risk factor $\times$ genotype: } \\
\hline$G \times A g e$ & $\uparrow^{*}$ & - & - & - & - & - \\
\hline $\mathrm{G} \times$ Marriage & - & - & - & $\downarrow^{* * *}$ & - & - \\
\hline $\mathrm{G} \times$ Children & - & $\downarrow^{*}$ & - & - & - & - \\
\hline $\mathrm{G} \times$ Smoking & - & - & $\downarrow^{*}$ & - & - & - \\
\hline $\mathrm{N} \times$ Education & - & - & - & $\uparrow^{*}$ & - & - \\
\hline $\mathrm{N} \times$ Children & - & - & $\uparrow^{*}$ & - & - & - \\
\hline $\mathrm{N} \times$ Alcohol & - & $\uparrow * *$ & - & - & - & - \\
\hline $\mathrm{N} \times$ Tea & $\uparrow * *$ & - & - & - & - & - \\
\hline $\mathrm{N} \times$ Coffee & - & - & $\downarrow^{*}$ & - & - & - \\
\hline $\mathrm{E} \times$ Children & - & - & $\uparrow^{*}$ & - & - & - \\
\hline $\mathrm{E} \times$ Smoking & - & - & - & - & $\uparrow^{*}$ & - \\
\hline
\end{tabular}

$\uparrow$ denotes increased risk, $\downarrow$ denotes decreased risk. Asterisks denote significance level $\left({ }^{*} 5 \% ;{ }^{*} 1 \% ;{ }^{* * *} 0.1 \%\right.$ significance level) at the time a term was first entered into the regression equation. Parentheses indicate a variable is not a significant predictor once terms for genetic effects and genotype $\times$ risk factor interaction are included in the regression equation.

$10.2 \%$ to $30.3 \%$ of the variance, and the effect of extraversion was just short of significance $(F=2.82$, $P=0.09)$. In both sexes, individuals reporting disturbed sleep tended to be more neurotic, and more likely to report symptoms of anxiety and depression.

Prediction of scores on the second and third components did not improve so markedly. Inclusion of symptom and personality measures for females led to an increase in proportion of variance accounted for from $14.7 \%$ to $16.2 \%$ for short-sleep, and from $16.7 \%$ to $19.6 \%$ for frequent napping. Corresponding increases in mal es were from $17.7 \%$ to $18.3 \%$ and from $25.9 \%$ to $27.5 \%$. Both female and male short sleepers are more extroverted $\left(F_{1,3008}=34.41, P<0.001 ; F_{1,1437}=7.72, P<0.01\right)$ and less neurotic $(F=13.02, P<0.001 ; F=3.26$, $P=0.07)$ than long sleepers. Females who report that they often nap during the day, tend to wake at night and do not sleep very deeply are more introverted $\left(F_{1,3016}=5.61, P<0.02\right)$, but al so report fewer symptoms of anxiety $(F=25.06, P<0.001)$ and depression $(F=13.32, P<0.001)$. Male shallow sleepers who regularly take naps also report fewer symptoms of depression $\quad\left(F_{1,1436}=25.86\right.$, $P<0.001)$

\section{Genotype-risk factor correlation}

We also examined the improvement in prediction when the epidemiological variables, and terms for their interaction with genotype, were entered into the regression equation after age, genetic effects (ie terms for the interaction of zygosity and co-twin's scores), and own personality and symptoms. The proportion of variation explained increased from $35.9 \%$ to $36.3 \%$ and $28.5 \%$ to $29.8 \%$ for sleep disturbance in females and males respectively; from $11.5 \%$ to $16.0 \%$ and $11.8 \%$ to $18.3 \%$ for short-sleep; and from $17.3 \%$ to $19.4 \%$, and $25.1 \%$ to $27.3 \%$ for frequent napping. These data give little support to the notion that lifestyle and other epidemiological risk-factors have a major causal effect on sleep disturbance, particularly in females. They suggest rather that the apparent association between risk factors and sleep disturbance observed in the initial analyses is a consequence of the separate effects of symptoms and personality on lifestyle and on sleep. 
For short-sleep versus long-sleep, how ever, aspects of lifestyle are still found to be important predictors.

Table 5 identifies the epidemiological variables which, either as main effects or in interaction with genotype, remained significant predictors of sleep disturbance and sleep pattern even when personality and recent symptoms of anxiety and depression were taken into account. For sleep disturbance, we find that the number of epidemiological variables having significant main effects or significant effects in interaction with genotype has been reduced to six. Only two of these, smoking and alcohol consumption, are modifiable habits, and neither of these is having any effect on sleep disturbance in females. For short-sleep, only five variables are having effects which are independent of genotype, and only two of these are influencing short-sleep in males. Only in the case of frequent napping associated with shallow sleep do we find essentially the same epidemiological predictors to be important. Indeed, in this case two more three-way interaction terms have reached significance at the $5 \%$ significance level, indicating significant genotype $\times$ age interaction and a significant interaction of genes for neuroticism with marital status in males.

\section{Discussion}

\section{Representativeness of the sample}

There are no good normative data on sleep patterns in Australia, to which the present data could be compared. Enrolment in the Australian National Health and Medical Research Council Twin Register was voluntary, a disproportionate number of volunteers being young, female, and from monozygotic twin pairs. ${ }^{34}$ We have how ever controlled for age and sex effects on sleep, by taking out the regression of our derived sleep variables on age, and conducting separate analyses for males and females. We know that this sample does not differ from the general population of Australia in respect of its personality characteristics, ${ }^{61}$ or the prevalence of symptoms of anxiety and depression. ${ }^{35}$ It seems unlikely, therefore, that the unrepresentativeness of the sample will have seriously biased our conclusions about the causes of sleep disturbance and sleep pattern.

\section{The validity of self report data}

The Australian twin survey relied entirely upon subjective assessments of usual quality and timing of

Table 5 Major epidemiological predictors of sleep disturbance and sleep pattern, after allowing for the effects of personality and symptoms of anxiety and depression

\begin{tabular}{|c|c|c|c|c|c|c|}
\hline & $\begin{array}{l}\text { Sleep disturbance } \\
\text { Female }\end{array}$ & Male & $\begin{array}{l}\text { Short sleep } \\
\text { Female }\end{array}$ & Male & $\begin{array}{l}\text { Frequent } \\
\text { shallow } \\
\text { Female }\end{array}$ & Male \\
\hline \multicolumn{7}{|l|}{ Epidemiological: } \\
\hline Age & $\uparrow^{* *}$ & $\uparrow^{*}$ & $\uparrow^{* *}$ & - & $\uparrow * * *$ & $\uparrow^{* * *}$ \\
\hline Education & - & - & $\uparrow * * *$ & $\uparrow^{* * *}$ & - & $\downarrow^{* *}$ \\
\hline Marriage & $\downarrow^{* *}$ & $\downarrow^{* *}$ & - & - & $\uparrow * * *$ & $\uparrow * *$ \\
\hline Children & - & $\uparrow * * *$ & $\downarrow^{* * *}$ & - & - & - \\
\hline Alcohol & - & - & - & - & - & $\uparrow^{* *}$ \\
\hline Tea & _- & - & _- & - & _- & - \\
\hline Coffee & - & - & $\uparrow^{* * *}$ & $\uparrow * * *$ & - & - \\
\hline Exercise & - & - & - & - & - & - \\
\hline Smoking & - & $\downarrow^{* * *}$ & $\uparrow^{* * *}$ & - & $\downarrow^{* * *}$ & - \\
\hline \multicolumn{7}{|c|}{ Risk factor $\times$ genotype: } \\
\hline$G \times A g e$ & $\uparrow^{* *}$ & - & - & - & _- & $\uparrow^{*}$ \\
\hline $\mathrm{G} \times$ Education & - & $\uparrow^{*}$ & - & - & - & - \\
\hline $\mathrm{G} \times$ Marriage & - & - & $\downarrow^{* * *}$ & $\downarrow$ ** & - & - \\
\hline $\mathrm{G} \times \mathrm{Alcohol}$ & - & - & $\downarrow^{* * *}$ & - & - & - \\
\hline $\mathrm{G} \times$ Smoking & - & - & $\downarrow^{*}$ & - & - & - \\
\hline $\mathrm{N} \times$ Education & - & - & - & $\uparrow^{*}$ & - & - \\
\hline $\mathrm{N} \times \mathrm{Marriage}$ & - & - & - & - & - & $\downarrow^{*}$ \\
\hline $\mathrm{N} \times$ Children & - & - & $\uparrow^{*}$ & $\uparrow^{*}$ & - & - \\
\hline $\mathrm{N} \times$ Alcohol & - & $\uparrow^{* *}$ & - & - & - & - \\
\hline $\mathrm{N} \times$ Tea & - & - & $\downarrow^{*}$ & - & - & - \\
\hline $\mathrm{N} \times$ Coffee & - & - & $\uparrow^{*}$ & - & - & - \\
\hline $\mathrm{E} \times$ Marriage & - & - & $\downarrow^{*}$ & - & - & - \\
\hline $\mathrm{E} \times \mathrm{Tea}$ & - & - & - & $\uparrow^{*}$ & - & - \\
\hline$E \times$ Smoking & - & - & - & - & $\uparrow * *$ & - \\
\hline
\end{tabular}

$\uparrow$ denotes increased risk, $\downarrow$ denotes decreased risk. Asterisks denote significance level $\left({ }^{*} 5 \% ;{ }^{* *} 1 \% ;{ }^{* * *} 0.1 \%\right.$ significance level) at the time a term was first entered into the regression equation. Parentheses indicate a variable is not a significant predictor once terms for genetic effects and genotype $\times$ risk factor interaction are included in the regression equation. 
sleep. This is inevitable, since the very large sample sizes required for genetic research ${ }^{62}$ could not be achieved in a sleep laboratory-based study. Moreover, it is these same subjective assessments of sleep which form the basis for most use of hypnotic and non-prescription medication., 2

When subjective estimates of sleep have been validated against EEG recordings in the sleep laboratory, poor sleepers have regularly been found to overestimate sleep latency and underestimate total sleep duration, but al so to underestimate how often they awaken fully from sleep. ${ }^{7,63,64}$ Such studies are usually able to confirm the existence of sleep difficulties, even if they have been exaggerated. Normal sleepers are able to give a more accurate report of their sleep latency. ${ }^{7}$ One possible interpretation of the findings for sleep latency and duration is that poor sleepers are genetically sensitised to disturbances and other risk factors which are minimised in the artificial environment of the sleep laboratory. If, as seems likely, they are using subjective information about their usual sleep latency and sleep duration in the home environment in assessing sleep in the sleep laboratory, this would explain the observed results. How ever, our analyses have failed to find evidence for a major effect of genotype $\times$ risk factor interaction on either sleep pattern or sleep disturbance, suggesting that the results of sleep laboratory studies may not be seriously misleading.

The questionnaire measures of sleep pattern and sleep disturbance used in the survey have previously been validated against laboratory-based EEG measures of sleep. ${ }^{58}$ An important feature of the survey is that it combines multiple subjective measures of sleep disturbance and sleep quality with estimates of sleep latency and sleep duration. This provides one check on the validity of the measures, that of internal consistency: those individuals in the sample who report frequent difficulty falling asleep ('initial insomnia') or sleep difficulty associated with depressed or anxious effect al so report a longer sl eep latency and a shorter sleep duration, and are more likely to report poor or variable quality and shallowness of sleep (see Table 3). Thus we can be confident that those who complain of regular difficulty falling asleep, while perhaps falling asleep more quickly than they report, are nevertheless taking longer to fall asleep than those who do not report such difficulties, and experiencing distress as a result.

\section{Genetic influences}

In both sexes we found significant genetic effects on sleep disturbance, short-sleep and shallow sleep associated with napping during the day, which could not be explained by genetic effects on lifestyle variables such as alcohol consumption and smoking. Some of this genetic variation could be explained by the effects on sleep of the personality traits of neuroticism and extraversion, which are known to be strongly influenced by genetic factors. ${ }^{43}$ Additional genetic variation could be attributed to the effects of genetic liability to symptoms of anxiety and depression. ${ }^{34-36}$ Nonetheless, strong evidence was found for residual genetic variation in sleep disturbance and sleep pattern which could not be explained by any intervening variables.

From the results of the principal components analysis it appears that sleep disturbance is, to a remarkable degree, independent of sleep pattern. Loadings of the variables 'bedtime', 'sleeptime' and "daytime napping" on the first component (sleep disturbance) are comparatively small in both sexes, and loadings of the subjective sleep disturbance variables and "daytime napping" on the second component (sleep pattern) are even smaller. This suggests that different sets of genes are determining liability to sleep disturbance, short-sleep, and daytime napping. Further analyses have confirmed the biological independence of sleep pattern and sleep disturbance. ${ }^{37}$.

Unexpectedly, we found little evidence for genotype $\times$ age interaction for the short-sleep vs long-sleep and daytime napping component scores. This implies that biological influences on sleep pattern are acting with remarkable consistency throughout the life span (see al so Heath et $\mathrm{al}^{37}$ for further modelfitting analyses confirming this finding). Even for sleep disturbance, significant genotype $\times$ age interaction was observed only in females, and accounted for only a small proportion of the variation. Such consistency is difficult to reconcile with the view that the excess similarity of $\mathrm{MZ}$ twins, compared with DZ twins, is due to the greater similarity of their experiences during childhood (see Kendler ${ }^{65}$ for other criticisms of this argument).

\section{Epidemiological predictors}

Our analyses indicate that lifestyle variables such as smoking and consumption of al cohol, tea and coffee, and demographic and situational variables such as educational level, marital status and number of children, explain a relatively small proportion of the variance in sleep disturbance and sleep pattern. When associations between epidemiological predictors and sleep are considered without taking account of current symptoms and personality, the causal effects of these variables on sleep is overestimated (compare Tables 4 and 5). At least part of the association appears to be explained by the separate effects of symptoms and personality on lifestyle and sleep. This effect is particularly pronounced in the 
case of female sleep disturbance, where, after allowing for symptoms and personality, the only significant epidemiological predictors are age and marriage. Associations between sleep and frequency of exercise appear to be entirely explained by the effects of symptoms and personality on both.

Smoking and alcohol consumption are the lifestyle variables which best predict sleep disturbance and sleep pattern. In males, alcohol consumption is associated with increased frequency of napping and shallow sleep, and (particularly in those with high genetic liability to neuroticism) with increased complaints of sleep disturbance. In females, alcohol consumption tends to exacerbate any genetic tendency to long-sleep. Smoking (in femal es) and coffee consumption (males and females) are associated with short-sleep. Smoking al so shows an unexpected association, in males, with decreased frequency of complaints of sleep disturbance and decreased frequency of napping together with increased depth of sleep. Further analysis (unpublished) suggests that these findings are largely explained by the increased number of smokers who report 'deep' sleep, ie that they are 'hard to wake'. This association should not therefore be interpreted as a beneficial effect of smoking on sleep.

Education, marriage and having one or more children emerge as important epidemiological predictors of sleep disturbance and sleep pattern. The protective effects of marriage against sleep disturbance are counteracted (at least in males) by having children! Married individuals report greater frequency of sleep during the day and longer sleep duration, and females with children also report longer sleep duration at night. High education is associated with shorter sleep duration in both sexes, but also increased depth of sleep and decreased frequency of napping (at least in males).

\section{Genotype $\times$ risk factor interaction}

Genotype $\times$ risk factor interaction explains only a small proportion of the variation in sleep disturbance and sleep pattern. This probably reflects the unexpectedly small impact of epidemiological variables on sleep. Several risk factors show associations with short-sleep, in particular, only in interaction with genotype.

\section{Conclusions}

Our analyses suggest that much of the variance in subjective sleep disturbance and sleep pattern can be explained by genetic factors, personality, and current symptoms of anxiety and depression. A spects of lifestyle and other epidemiological variables are comparatively unimportant. Some of the association between lifestyle and sleep is explained by the separate effects of symptoms and personality on lifestyle and on sleep (genotype-risk factor correlation). Many of the epidemiological variables which do influence sleep have effects which interact with genotype (genotype $\times$ risk factor interaction), but these interactions still explain only a comparatively small proportion of the variance.

\section{Acknowledgements}

This work was supported in part by ADMHA grants AA06781 and AA07728, by NIH grants GM30250, HL28922, A G04954, GN32732, HD15838, HL31010 and DE05139, by a grant from the Australian National Health and Medical Research Council, and by the Department of Mental Health and Mental Retardation of the Commonwealth of Virginia. We are grateful to Dr Greg Carey for helpful comments on an early draft of this manuscript.

\section{References}

1 National Center for Health Statistics. Selected Symptoms of Psychological Distress. US Public Health Service Publication 1000, Series 11, Number 37. US Department of Health, Education and Welfare: Washington DC, 1970.

2 Balter MB, Bauer ML. Patterns of prescribing and use of hypnotic drugs in the United States. In: Clift AD (ed.). Sleep Disturbances and Hypnotic Drug Dependence. Excerpta Medica: New York, 1975.

3 Karacan I, Thornby J, Anch M, Holzer CE, Warheit GJ, Schwab $W$, Williams RL. Preval ence of sleep disturbance in a primarily urban Florida county. Soc Sci Med 1976; 10: 239-244.

4 Bixler EO, Kales A, Soldatos CR, Kales D, Healey S. Preval ence of sleep disorders in the Los Angel es Metropolitan Area. Am J Psychiatry 1979; 136: 1257-1262.

5 Welstein L, Dement WC, Redington D, Guilleminault C, Mitler MM. Insomnia in the San Francisco Bay Area: a Telephone Survey. In: Guilleminault C, Lugaresi E (eds). Sleep/Wake Disorders: Natural History, Epidemiology, and Long-term Evolution. Raven Press: New York, 1983.

6 Mellinger GD, Balter MB, Uhlenhuth $\mathrm{EH}$. Insomnia and its treatment. Prevalence and correlates. Arch Gen Psychiatry 1985; 42: 225-232.

7 Johnson LC, Spinweber CL. Quality of sleep and performance in the Navy: a longitudinal study of good and poor sleepers. In: Guilleminault C, Lugaresi E (eds). Sleep/Wake Disorders: Natural History, Epidemiology, and Long-term Evolution. Raven Press: New York, 1983, pp 13-28.

8 Hammond E. Some preliminary findings on physical complaints from a prospective study of $1,064,000$ men and women. Am J Pub Health 1964; 54: 11-23. 
9 Hammond E, Garfinkel L. Coronary heart disease, stroke, and aortic aneurysm. Factors in the etiology. Arch Environ Health 1969; 19: 167-182.

10 Kripke D, Simons R, Garfinkel L, Hammond E. Short and Iong sleep and sleeping pills. Is increased mortality associated? Arch Gen Psychiatry 1979; 36: 103-116.

11 Belloc NB, Breslow L. Relationship of physical health status and health practices. Prev Med 1972; 1: 409-421.

12 Belloc NB. Relationship of heal th practices and mortality. Prev Med 1973; 2: 67-81.

13 McGhie A, Russell SM. The subjective assessment of normal sleep patterns. JMent Sci 1962; 108: 642-654.

14 Lugaresi E, Cirignotta F, Zucconi M, Nondini S, Lenzi PL, Coccagna G. Good and poor sleepers: an epidemiological survey of the San Marino Population. In: Guilleminault C, Lugaresi E (eds). Sleep/Wake Disorders: Natural History, Epidemiology, and Long-term Evolution. Raven Press: New York, 1983.

15 Karacan I, Thornby $\mathbf{J}$, Williams RL. Sleep disturbance: a community survey. In: Guilleminault C, Lugaresi E (eds). Sleep/Wake Disorders: Natural History, Epidemiology, and Long-term Evolution. Raven Press: New York, 1983, p 14.

16 Lavie P. Sleep habits and sleep disturbances in industrial workers in Israel: main findings and some characteristics of workers complaining of excessive daytime sleepiness. Sleep 1981; 4: 147-158.

17 Palmer CD, Harrison GA, Hiorns RW. Sleep patterns and life style in Oxfordshire villages. J Biosoc Sci 1980; 12: 437-467.

18 Palmer CD, Harrison GA, Hiorns RW. Association between smoking and drinking and sleep duration. Ann Hum Biol 1980; 7: 103-107.

19 Palmer CD, Harrison GA. Intercorrelations between sleep and activity patterns in Otmoor Villagers. Hum Biol 1983; 55: 749-762

20 Palmer CD, Harrison GA. Sleep latency and lifestyle in Oxfordshire villages. Ann Hum Biol 1983; 10: 415-428.

21 Phillips BA, Danner FJ. Cigarette smoking and sleep disturbance. Arch Int Med 1995; 155: 734-737.

22 Valatx $\mathbf{L}$, Bugat R, Juvet M. Genetic studies of sleep in mice. Nature 1972; 238: 226-227.

23 Friedmann K. A diallel analysis of the genetic underpinnings of mouse sleep. Physiol Behav 1974; 12: 169-175

24 Linkowski P, Kerkhofs M, Hauspie R, Susanne C, Mendlewicz J. EEG sleep patterns in man: a twin study. Electroencephalgr Clin Neurophysiol 1989; 73: 279-284

25 Linkowski P, Kerkhofs M, Hauspie R, Mendelwicz J. Genetic determinants of EEG sleep: a study in twins living apart. Electroencephalgr Clin Neurophysiol 1991; 79: 114-118.

26 Hublin C, Kaprio J, Partinen M, Heikkila K, Koskenvuo M. Prevalence and genetics of sleepwalking: a population-based twin study. Neurology 1997; 48: 177-181.

27 Kaprio J, Hublin C, Partinen M, Heikkila K, Koskenvuo M. Narcolepsy-like symptoms among adult twins. J Sleep Res 1996; 5: 55-60.

28 Planelles D, Puig N, Beneto A, Gomez E, Rubio P, Mirabet V, Bonanad S, Blasco I, Montoro JA. HLA-DQA, -DQB and -DRB allele contribution to narcolepsy susceptibility. Eur JImmunogenet $1997 ; 24:$ 409-421.

29 Mignot E. Genetic and familial aspects of narcolepsy. Neurology 1998; 50: S16-S22.

30 Honda T, Asaka A, Tanimura M, Furusho T. A genetic study of narcolepsy and excessive daytime sleepiness in 308 families with a narcolepsy or hypersomnia proband. In: Guilleminault C, Lugaresi E (eds). Sleep/Wake Disorders: Natural History, Epidemiology, and Long-term Evolution Raven Press: New York, 1983.

31 Roth B, Nevsimalova S, Rechtschaffen A. Hypersomnia with 'sleep drunkenness'. Arch Gen Psychiatry 1972; 26 : 456-462.
32 Redline S, Tosteson T, Tishler PV, Carskadon MA, Millman RP. Studies in the genetics of Obstructive Sleep Apnea I. Familial aggregation of symptoms associated with sleep-related breathing disturbances. Am Rev Respir Dis 1992; 145: 440-444.

33 Partinen M, Kaprio J, Koskenvuo M, Putkonen P, Langinvainio $\mathrm{H}$. Genetic and environmental determination of human sleep. Sleep 1983; 6: 179-185.

34 Jardine R, Martin NG, Henderson AS. Genetic covariation between neuroticism and the symptoms of anxiety and depression. Genet Epidemiol 1984; 1: 89-107.

35 Kendler KS, Heath A, Martin NG, Eaves LJ. Symptoms of anxiety and depression in a volunteer twin population: the etiologic role of genetic and environmental factors. Arch Gen Psychiatry 1986; 43: 213-221.

36 Kendler KS, Heath AC, Martin NG, Eaves LJ. Symptoms of anxiety and depression: same genes, different environments ? Arch Gen Psychiatry 1987; 44: 451-457.

37 Heath AC, Kendler KS, Eaves LJ, Martin NG. Evidence for genetic influences on sleep disturbance and sleep pattern in twins. Sleep 1990; 13: 318-335.

38 Eaves LJ, Last K, Martin NG, Young PA. A progressive approach to non-additivity and genotype-environmental covariance in the anal ysis of human differences. Br JMath Stat Psychol 1977; 30: 1-42.

39 Eaves LJ. The resolution of genotype $\times$ environment interaction in segregation analysis of nuclear families. Genet Epidemiol 1984; 1: 215-228.

40 Heath AC, Berg K, Eaves LJ, Solass MH, Corey LA, Sundet J, Magnus $P$, Nance WE. Education policy and the heritability of educational attainment. Nature 1985; 314: 734-736.

41 Kendler KS, Eaves LJ. Models for the joint effect of genotype and environment on liability to psychiatric illness. Am J Psychiatry 1986; 143: 279-289.

42 Jardine R, Martin NG. Causes of variation in drinking habits in a large twin sample. Acta Genet Med Gemellol (Roma) 1984; 33: 435-450.

43 Eaves LJ, Eysenck HJ, Martin NG, Jardine R, Heath AC, Feingold L, Young PA, Kendler KS. Genes, Culture and Personality: an Empirical Approach Academic Press: London, 1989

44 Eaves LJ, Eysenck HJ. The genetics of smoking. In: Eysenck, HJ (ed.). The Causes and Effects of Smoking. Temple-Smith: London, 1980, pp 158-314.

45 Hannah MC, Hopper $\mathbf{L}$, Mathews $\mathbf{D}$. Twin concordance for a binary trait. II. Nested analysis of ever-smoking and ex-smoking traits and unnested analysis of a 'committedsmoking' trait. Am JHum Genet 1985; 37: 153-165.

46 Carmelli D, Swan GE, Robinette D, Fabsitz RR. Heritability of substance use in the NAS-NRC Twin Registry. Acta Genet Med Gemellol (Roma) 1990; 39: 91-98.

47 Johns MW, Gay TJA, Goodyear MDE, Masterton J. Sleep habits of heal thy young adults: use of a sleep questionnaire. $\mathrm{Br}$ JPrev Soc Med 1971; 25: 236-241.

48 Johns MW. Methods for assessing human sleep. Arch Int Med 1971; 127: 484.

49 Johns MW. Factor analysis for subjectively reported sleep habits, and the nature of insomnia. Psychol Med 1975; 5: 83-88.

50 Bedford A, Foulds GA, Sheffield BF. A new personal disturbance scale (DSSI/SAD). Br J Soc Clin Psychol 1976; 15: 387-394.

51 Bedford A, Deary IJ. The personal disturbance scale (DSSI/ SAD): development, use and structure. Person Individ Diff 1997; 22: 493-510.

52 Eysenck HJ, Eysenck SBG. Personality Questionnaire (Junior and Adult). Hodder and Stoughton Educational: London, 1975

53 Cederlof R, Friberg L, Jonsson E, Kaij L. Studies on similarity diagnosis in twins with the aid of mailed questionnaires. Acta Genet Stat Med 1961; 11: 338-362. 
54 Nichols RC, Bilbro WC. The diagnosis of twin zygosity. Acta Genet Stat Med 1966; 16: 265-275.

55 Martin NG, Martin PG. The inheritance of scholastic abilities in a sample of twins. I. Ascertainment of the sample and diagnosis of zygosity. Ann Hum Genet 1975; 39: 213-218.

56 Kasriel J, Eaves LJ. A comparison of the accuracy of written questionnaires with blood-typing for diagnosing zygosity in twins. J Biosoc Sci 1976; 8: 263-266.

57 Magnus P, Berg K, Nance WE. Predicting zygosity in Norwegian twin pairs born 1915-1960. Clin Genet 1983; 24: 103-112.

58 Lewis SA. Subjective estimates of sleep: an EEG eval uation. $\mathrm{Br}$ J Psychol 1976; 60: 203.

59 DeFries JC, Fulker DW. Multiple regression analysis of twin data. Behav Genet 1985; 15: 467-473.

60 Eaves LJ. The utility of twins. In: Anderson VE (ed.). Genetic Basis of the Epilepsies. Raven Press: New York, 1982.
61 Martin NG, Jardine R. Eysenck's contributions to behaviour genetics. In: Modgil S, Modgil C (eds). Hans Eysenck: Consensus and Controversy. Falmer Press: Philadel phia, 1986, pp 13-47.

62 Martin NG, Eaves LJ, Kearsey MJ, Davies P. The power of the classical twin study. Heredity 1978; 40: 97-116.

63 Bixler EO, Kales D, Leo LA, Slye T. A comparison of subjective estimates and objective sl eep laboratory findings in insomniac patients. Sleep Res 1973; 2: 143.

64 Carskadon MA, Dement WC, Mitler NM, Guilleminault C, Zarcone VP, Spiegel R. Self-reports versus sleep laboratory findings in 122 drug-free subjects with complaints of chronic insomnia. Am J Psychiatry 1976; 133: 1382-1388.

65 Kendler KS. Overview: A current perspective on twin studies of schizophrenia. Am JPsychiatry 1983; 140: 1413-1425. 